\title{
Indigenismos antillanos e imagen visual: México, ¿un referente?
}

\section{Antillean Indigenisms and Visual Image: Mexico, a Reference?}

\section{Yolanda Wood Pujols*}

Resumen: En el proceso de fundación de una imagen en las grandes Antillas durante las primeras décadas del siglo XX, se produjo una mirada hacia lo primigenio y autóctono como una forma de recuperación de "lo propio" cuando los territorios vivían en circunstancias históricas de inestabilidad políitica y ocupación extranjera. El texto estudia las características de los indigenismos antillanos en la construcción de una identidad nacional y en la configuración de los imaginarios culturales. Se indagan sus relaciones con el indigenismo mexicano como referente y se valoran tendencias visuales diversas a través de autores y obras en los territorios que integran la muestra. El estudio se realiza con una perspectiva interdisciplinaria y comparada a partir de los estudios visuales, y el empleo de fuentes que problematizan los significados de los indigenismos antillanos en sus contextos.

Palabras clave: Indigenismo; Antillas; Identidad; Imaginarios.

Abstract: In the process of founding an image in the Greater Antilles during the first decades of the twentieth century, there was a focus the primitive and autochthonous as a way of recovering "one's own" when the territories lived in historical circumstances of political instability and foreign occupation. The text studies the characteristics of Antillean indigenisms in the construction of a national identity and in the configuration of cultural imaginaries. Their relations with Mexican indigenismo are investigated as a reference and diverse visual tendencies are valued through authors and works in the territories that make up the sample. The study is carried out with an interdisciplinary and comparative perspective from visual studies, and the use of sources that problematize the meanings of Antillean indigenisms in their contexts.

KEY WORDS: Indigenism; Antilles; Identity; Imaginaries.

Recibido: 7 de junio de 2018

Aceptado: 22 de agosto de 2018

Departamento de Arte-Universidad de La Habana (yolawood@gmail.com). 


\section{INTRODUCCIÓN $^{1}$}

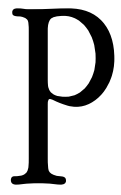

ensar la interculturalidad de Las Antillas supone situarlas en los ejes de dos matrices referenciales: la europea y la africana, ambas consustanciales a la formación de lo local y nacional en sus culturas, con todas las diversidades que caracterizan ese archipiélago. La extendida tendencia a creer en la exterminación "total" de la población indígena hace menos evidente esta matriz en la cultura antillana. Sin embargo, cuando se intentó la fundación de una imagen en circunstancias históricas muy complejas para las grandes Antillas, esa "matriz ausente" fue parte constitutiva del ser cultural antillano como acto de reivindicación ancestral, como expresión descolonizadora y como ejercicio de poder. Hubo antecedentes, sobre todo en las literaturas de esos países en la segunda mitad del siglo XIX, de una presencia indígena, como la novela Enriquillo en República Dominicana, el movimiento literario cubano llamado siboneyismo y otros estudios de carácter académico como los del puertorriqueño Alejandro Tapia y Rivera a propósito de los taínos, y por supuesto el gran acto de reivindicación de los libertadores haitianos al llamar a Saint Domingue con su nombre original, Ayiti. Durante las primeras décadas del pasado siglo, en México había crecido un movimiento - también renovador - que tuvo como fuente de legitimación cultural el universo indígena, lo que significó un referente, con matices diversos y polémicos para Las Antillas, para el reencuentro cultural con "nosotros mismos", dentro del debate crítico que implicó el acto fundacional de una visualidad antillana y sus procesos ulteriores de desarrollo artístico.

1 Deseo expresar mi agradecimiento por la excelente oportunidad de trabajo que me ofreció el Programa de Estancia de Investigación (PREI) de la UNAM, en particular a la Dirección General de Asuntos del Personal Académico (DGAPA), la Coordinación de Investigaciones de la Facultad de Filosofía y Letras, el Colegio de Estudios Latinoamericanos bajo la coordinación del doctor Sergio Ugalde y la orientación del doctor Miguel Ángel Esquivel. A todos, gracias. Agradezco la cesión de derechos de publicación de las imágenes que acompañan este texto a las instituciones donde se albergan las obras. 
INDIGENISMO: PENSAMIENTO SOCIAL

E IMAGINARIOS CULTURALES

El indigenismo fue una de las más importantes tendencias del pensamiento nacionalista durante las primeras décadas del siglo Xx en Latinoamérica; buscaba expresar los fundamentos históricos de un pasado que había padecido los embates de la conquista y la colonización. El indigenismo aportó una reivindicación de los tiempos originarios, entendidos en esos planos complejos de la modernidad-colonialidad, al asumir posturas críticas ante el poder dominante hispano. Se insertó como tendencia de pensamiento social en un trayecto de búsquedas para fundar la imagen de lo propio en las artes, tomando referencias de aquellos que habían quedado como "peregrinos en su propia tierra" (Brading 2004: 23).

Explorar el tema de los indigenismos en la cartografía antillana supone una delimitación territorial dentro del conjunto de islas que conforman ese archipiélago. De acuerdo con las circunstancias histórico-sociales que vivían los territorios, se distinguen para este estudio los países que forman el arco mayor antillano: Cuba, Haití, República Dominicana y Puerto Rico, los que durante esos años se confrontaban en procesos identitarios de expresión nacionalista en lo social y en los campos de la cultura y las artes, en condiciones muy complejas por la injerencia de Estados Unidos a partir de la mal llamada Guerra hispano-cubano-americana al estar involucrado también Puerto Rico en ese traspaso de poderes, de unas manos coloniales a otras, así como en los procesos que siguieron con la ocupación de Haití y la República Dominicana.

De modo que, si algo en común define la geopolítica antillana en las islas mayores de las Antillas por esos años es justamente la irrupción imperial del vecino del norte, iniciada en $1898,{ }^{2}$ que consideraba al mar de tantas islas como su traspatio y que se extendió también a los otros territorios caribeños mencionados, los únicos independientes en aquellos años. Se inauguraron así nuevas formas de dependencia neocolonial. Fueron, a

2 Con su antecedente en los territorios del norte de México en 1848. 
la vez, años que, en sus contradicciones, elevaron la conciencia crítica colectiva y contribuyeron a enaltecer el espíritu de reivindicación nacional.

¿Cómo entonces se entrecruzaron las ideas indigenistas con los proyectos nacionalistas en los territorios mayores del Caribe, y cómo se articularon con el pensamiento social y los imaginarios culturales sobre el pasado originario en los procesos identitarios? Conviene aclarar que se trataba de un momento de indagación y búsqueda de la expresión nacional que modulaba un discurso constructivo de la identidad, marcado por la propia diversidad de los contextos insulares. Lo interesante será revelar las dinámicas de reencuentro con el pasado, con los orígenes, como trayecto hacia la personalidad cultural de las naciones caribeñas. En general, el indigenismo fue una toma de posición ante lo propio y también un modo de revelar la nostalgia ante lo perdido.

Un indigenismo sin la presencia del indígena en Las Antillas se muestra como una significativa paradoja o como una metáfora para la definición de un ser cultural desde lo primigenio en el plano simbólico más que como la pertenencia étnica a una población demográficamente significativa, lo que ratifica - de una u otra manera - la esencia ideológica de la cuestión en sus especificidades antillanas. Aquellas poblaciones que no eran altamente numerosas en los territorios conquistados sufrieron el impacto que diezmó aún más sus colectividades por numerosas causas superpuestas que redujeron sensiblemente los pueblos originarios, los desplazaron y los concentraron hacia sitios cercanos a los nuevos asentamientos hispanos con el consiguiente rompimiento de la relación natural con su hábitat y sus formas de vida comunitarias.

Cómo explicar entonces que el indigenismo adquiriera el valor de una tendencia en el pensamiento y que se expresara con matices comunes y diferentes en las grandes Antillas. En general se trataba del reencuentro con "un principio", en una retrospectiva histórica que fue utilizada con diversas estrategias como gesto de una intelectualidad en un pensamiento reivindicativo de los valores culturales y de la identidad nacional, de igual modo como expresión del poder instaurado y sus maniobras políticas en la vida social y étnica de la nación, especialmente en lo relativo al mestiza- 
je, a lo criollo, a la subvaloración del negro, la revalorización de lo hispano o la sobrestimación de un origen glorioso que se evidenciaba también en los hallazgos arqueológicos.

Visto el proceso en ese orden y en los países mencionados, los contrastes resultan evidentes no sólo en relación con el referente latinoamericano continental, y mexicano en particular, con los que los países antillanos establecieron diferentes niveles de relación. México constituía la más próxima evidencia de un pensamiento nacionalista asentado en los orígenes que enaltecían la ancestralidad indígena como un pasado célebre y reivindicaba una matriz cultural que se mostraba viva y presente en el país, con habitantes en cantidades significativas para contribuir a diseñar políticas públicas de reconocimiento social. Bien que el indigenismo se desarrollaba en simultaneidad en otros territorios latinoamericanos, y especialmente en Perú con el ideario fundado por José Carlos Mariátegui y su revista Amauta, fue sin duda el de la Revolución mexicana y la admiración patriótica de un tiempo memorable, reflejado en las artes de México, en la obra monumental de los muralistas y en la exaltación de una autenticidad nacional indígena en el discurso nacionalista de José Vasconcelos desde la Secretaría de Educación Pública (1921), lo que situó el tema como parte del proyecto cultural del país con un intento de incorporación e integración asumido por el Estado. ${ }^{3}$

Al respecto, precisan los autores José del Val y Carlos Zolla que, "aunque pueda hablarse de una dimensión continental del indigenismo (como lo atestiguan las representaciones de los países en el Primer Congreso Indigenista Interamericano de 1940) es evidente también la singularidad del caso mexicano" (Val y Zolla 2014: 26). Situación similar no se podía producir en las islas antillanas, donde el indígena no tenía una presencia física en el acontecer de la vida nacional de las naciones, ni se había producido un proceso revolucionario como el que tuvo lugar en México. Por lo tanto esos indigenismos se orientaron en varias otras direcciones, lo

3 "El indigenismo mexicano es, esencialmente, una teoría, una política y una programática para la acción generadas e instauradas en el siglo xx a partir del proceso revolucionario" (Val y Zolla 2014: 31). 
que distingue "la polisémica riqueza y el campo de significaciones, la complejidad de la expresión indigenismo", pues más allá de lo semántico o lexicológico, "remite a teorías sociales, momentos históricos, perspectivas políticas [...] y acuñaciones ideológicas" (Val y Zolla 2014: 30).

En las islas se trató de otro orden discursivo, en el que el indio y lo indígena adquirieron valor cultural y simbólico en momentos de tensiones históricas antillanas que sin embargo presentaba ciertos síntomas comunes a las circunstancias en las que la política indigenista se enmarcó en el ámbito latinoamericano y mexicano, como por ejemplo, las intenciones de modernización, de búsqueda de una expresión nacional y de una identidad cultural. Entonces vale preguntarse, como lo hace Alberto Saladino García, "quién es el indio", quién es el que está gestando esta plataforma de pensamiento y actitudes, pues no necesariamente es él mismo como figura protagonista, no es su voz la que se escucha. Esos indigenismos hablan sobre él como sujeto cultural, un sujeto de identidad, que viaja del pasado al presente con las dimensiones ancestrales de la historia y que, aunque parece pertenecer a los tiempos que precedieron a la conquista, su imagen se actualiza y entra a la polémica realidad de otras circunstancias. Su imagen adquiere matices y valores nuevos, entre ellos valdría destacar que no necesariamente es un descendiente de los nativos originarios, pues su carácter simbólico remite a un principio más que a un origen genealógico y ese principio no desconoce la hispanidad, que se reivindica cuando un cambio de poderes coloniales amenaza con imponer la cultura del ocupante. Así ocurrió en Puerto Rico.

\section{UNA FIGURA DE IDENTIDAD PUERTORRIQUEÑA}

Los nombres originales de las islas en lengua aruaca ${ }^{4}$ han adquirido particular significado: Borinquen (así llamaron los antiguos habitantes a la isla de Puerto Rico), y su gentilicio, boricua, parecen estar tocados por

4 Lengua de América del Sur extendida por las islas a partir de los procesos migratorios de las comunidades que las poblaron desde el continente en sucesivas oleadas. 
el mágico sentimiento de una confirmación identitaria, porque traduce valores de pertenencia a una nación cultural. La mirada al pasado como respuesta a la nueva situación colonial remitió a una figura de identidad boricua: el jíbaro, que se hizo depositario de un conjunto de cualidades históricas y sociales. ${ }^{5}$

Cuando se lee la definición de "indio" que introduce Saladino García en su reflexión sobre el indigenismo, se refiere a un conjunto de rasgos sociales como " el despojo de sus medios de producción, la sobrexplotación servil de su fuerza de trabajo, la destrucción de su cultura y la imposición de elementos culturales ajenos" (Saladino 2016: 18). Vistos de esa manera, la condicionante única o esencial no resulta ser el origen étnico que, por demás, en los países antillanos quedaba inserta en el crisol de un nuevo pueblo, según la definición del antropólogo brasileño Darcy Riveiro, proceso que, en el espacio primigenio de contacto que fueron las islas del Caribe en la conquista y colonización, comenzó tempranamente.

El personaje del jíbaro se anclaba a la tierra y a la naturaleza, habitaba en ella y es esto lo que pone en valor su pertenencia a un lugar. Como ícono de identidad social fue distinguido selectivamente del conglomerado social, no era un indígena, era un personaje autóctono situado en la base misma del campesinado y asociado con la ruralidad. Privilegiar esas zonas significó desconocer otras, pero con él entró a la pintura la gente que revelaba, por su condición y estado de vida, las consecuencias de las economías deformadas por tanto desigual reparto de las riquezas y carencias seculares, que se actualizaban en la nueva situación dependiente y colonial: "el nuevo régimen tuvo el propósito de americanizar al puertorriqueño" (Landing 1986: 24), lo que produjo también agitaciones obreras y movimientos estudiantiles, así como una marcada resistencia intelectual hacia la asimilación cultural.

5 Como personaje literario, se encuentra en la novela El jíbaro, de Manuel Alonso y Tapia publicada en 1883, precisamente antes de la guerra del 98, cuando Puerto Rico era colonia de la corona española, y buscaba en su literatura elementos de identidad que lo diferenciaran, en este caso, de España. 
Regresar a la tierra y a la campiña era penetrar al interior del territorio como un cuerpo que se explora. Fue una alternativa para refundar el país desde lo social y lo cultural. La precariedad era un síntoma de las realidades insulares, su mayor padecimiento, un síndrome. Fue difícil sacar a estas personas de su anonimato. El arte, con la fuerza pregnante ${ }^{6}$ de su imagen, hizo un aporte fundamental al espíritu nacional. Hubo en ello una postura ética y una intención cognitiva trascendente. Un modo de proceder semejante a las propuestas del indigenismo mexicano sin que fuera tomado como referente. Se trató de un espíritu de época que en el caso puertorriqueño tenía al campesino como "la encarnación más depurada del alma nacional" (González 1980: 80).

En "El pan nuestro" (1904) de Ramón Frade (Figura 1), la figura humana domina en primer plano y "parece avanzar, como si fuera estrecho el límite para su grandeza pictórica en el marco que la encierra" (Delgado 1989: 71). ${ }^{9}$ El jíbaro es un símbolo ${ }^{10}$ y la pieza lo revela por su lugar en la composición, su frontalidad y su escala. Son los recursos del arte los que lo convierten en ícono visual, más allá de sus propios significados socioculturales, o justamente por esos propios valores. Se trata de un sujeto

6 La pregnancia es la fuerza visual de la forma. Es el poder que la forma ejerce sobre el movimiento ocular, así como su capacidad para imponerse como imagen mental y en el recuerdo.

7 Este tema no fue ajeno al debate sobre el indigenismo mexicano al reconocer al indígena, desde su propia definición, como el campesino que se encontraba en la base de la pirámide social, lo que produjo una polémica entre tendencias de un indigenismo antropológico y una tendencia social que llevó a afirmar a Luis Villoro que "el indio no existe $[. .$.$] en los países americanos sólo hay campesinos [...] los libertadores$ declararon a los indios ciudadanos y prohibieron que se les denominara así por discriminatorio" (Villoro 1950: 48).

8 De esta obra el propio autor realiza una réplica en 1936.

9 Recurso que se apreciará como tendencia en obras del arte mexicano posterior, el sobredimensionamiento de la escala humana.

${ }_{10} \mathrm{Al}$ referirse a este personaje de Frade en el "Pan nuestro", Ivón Muñiz dice "convertido erróneamente en el paradigma de lo nacional" (Muñiz 1990: 238). 


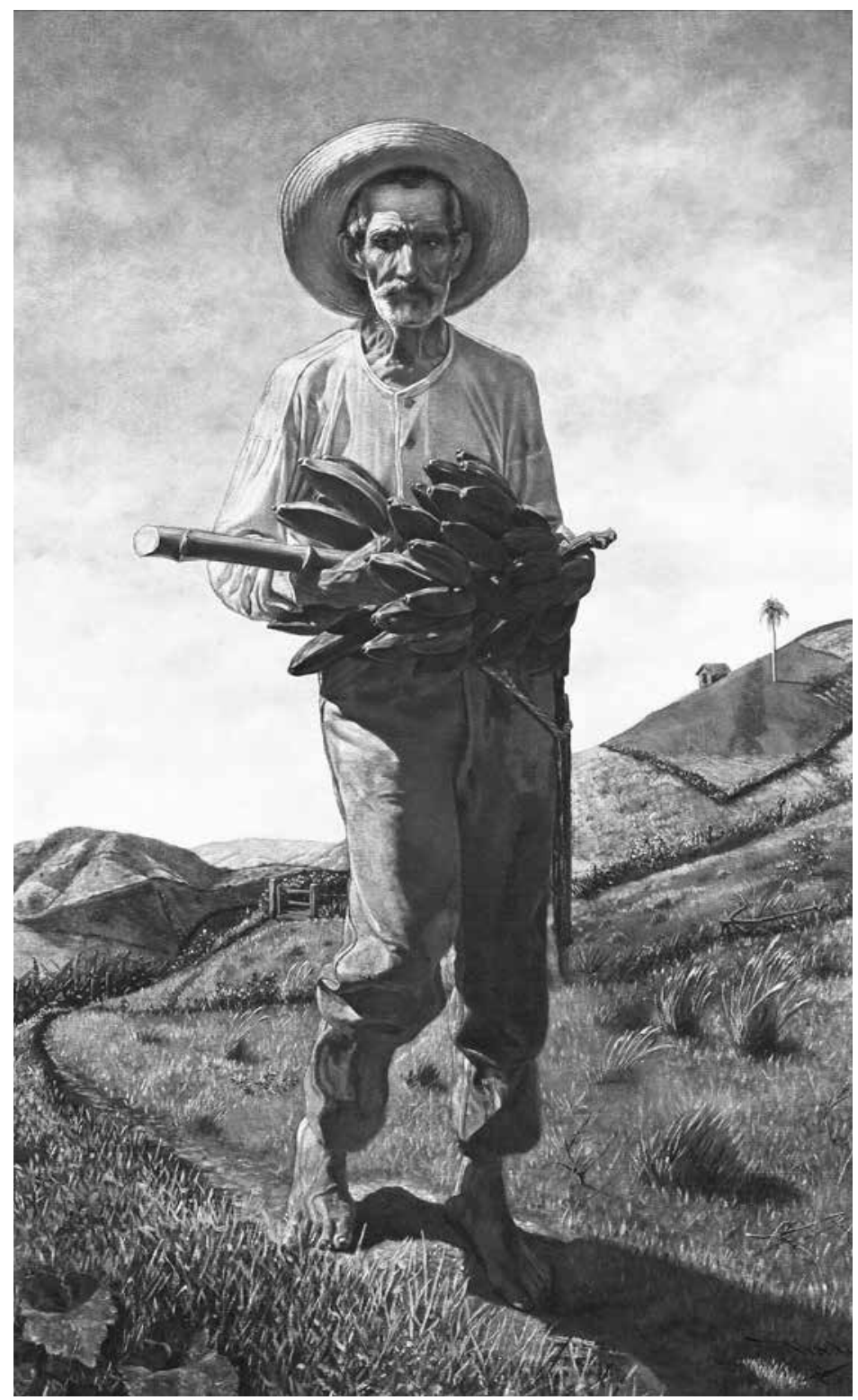

Figura 1. "El pan nuestro", Ramón Frade, 1905, óleo sobre lienzo. Colección Instituto de Cultura Puertorriqueña, San Juan, Puerto Rico. 
blanco y católico, ${ }^{11}$ por lo que su figura como atributo de identidad adquiere también connotaciones ideológicas pues, precisa Ivón Muñiz Rojas que

ante el inminente proceso de americanización muchos intelectuales se refugiaron en la herencia hispana como forma de salvaguardar la identidad nacional $[. .$.$] se produce una mirada atrás [. .$.$] se absolutiza la herencia$ y se falsifica. Se habla del campesino blanco como símbolo del pueblo boricua, excluyendo otras raíces. De ahí que surja un estereotipo: el jíbaro con su música, bailes, costumbres [... a a través de una óptica idealizada y romántica (Muñiz 1990: 238).

El jíbaro de Frade avanza hacia el espectador con los pies descalzos. El racimo de plátanos - cargado como una ofrenda - es una metafórica alusión al título de la obra y adelanta con él, desde la profundidad del cuadro, por un camino al parecer conocido y muchas veces transitado. En el paisaje no hay ni maleza, ni arboleda; es amplia la visibilidad del panorama natural nada frondoso ni exuberante. Predominan la soledad y el silencio. La dignidad de su imagen enaltece la marcha por el sendero. ${ }^{12}$ El artista había expresado: "Como todo lo puertorriqueño, se lo está llevando el viento, por eso lo pinto".

Osiris Delgado definió también al jíbaro como "el símbolo de un pueblo en estado de angustia" (Delgado 1976: 150), y se pregunta si se trata de una "nostalgia histórica". "De la tierra triste" (1921) es un cuadro melancólico, y "le llamé triste a mi tierra —dice el artista— porque en 1921 nos encontrábamos perdidos, descentrados, sin porvenir, sin norte. Le aseguro que la Isla era entonces una tierra [...] exenta de optimismo"

11 José Luis González ha identificado estas características del jíbaro con "la actitud conservadora asumida por la clase terrateniente marginada que desnaturalizó (la) realidad a través de su propia producción cultural proclamando la cultura popular del campesino blanco como la cultura popular por excelencia" (González 1980: 39).

12 Destaca Ivón Muñiz cómo la pintura puertorriqueña de esos años no se propuso "una ruptura y una negación con respecto a las propuestas estéticas del siglo anterior"; se refiere entonces a cierto estancamiento en ese sentido y a que "estuvieron de espaldas al desarrollo internacional del arte contemporáneo", y considera que se trató de "una actitud ideológica y rebeldía ante lo extraño, lo foráneo, que pudiera poner en desequilibrio la puertorriqueñidad" (Muñiz 1990: 235, 240). 
(Gaya 1994: 86). Hay algo de resignación y desconsuelo en estas imágenes, lo que también es común en ciertas representaciones del indígena en obras indigenistas. El jíbaro boricua es una imagen de la historia y, como el indígena en ciertas obras indigenistas, porta ese peso sobre sí mismo.

\section{REPÚBLICA DOMINICANA:}

INDIGENISTAS POR OPOSICIÓN

Desde su definición, uno de los más lúcidos autores sobre temas de antropología y arqueología dominicana, el novelista y ensayista Marcio Veloz Maggiolo, considera "la criollización", como un tipo de cultura diferente y cree que sólo con ese nombre "podríamos denominar la cultura dominicana" (Veloz 1980: 92). Él mismo ha sido un gran estudioso de los pueblos aborígenes de su país, de Las Antillas y de sus conexiones con los habitantes originarios de las tierras continentales. En su país la dimensión histórica de los cacicazgos y los descubrimientos arqueológicos ha revelado la existencia de comunidades con un alto nivel de producción simbólica tanto en su ajuar cotidiano como en su pensamiento mítico. Fue la pluma de Manuel de Jesús Galván la que escribió uno de los libros más necesarios al pensamiento indigenista antillano, Enriquillo, que fue calificado por José Martí como "poema americano", y en carta enviada al autor le decía que lo que allí había relatado "es cosa de toda nuestra América" (Galván 1989: 9). Con otros textos y autores, se funda, durante la segunda mitad del siglo XIX en República Dominicana, una literatura de corte romántico que enaltece al indio ante la confluencia de dos matrices que tensan la situación para la fundación de la nación dominicana, la haitiana y la española, una y otra confrontadas en sucesos históricos y políticos en el contexto de la isla compartida. ${ }^{13}$ García Arévalo sintetiza el proceso de esta manera: "se

13 Bernardo Vega precisa que "El movimiento indigenista en las letras dominicanas tuvo su causa de ser como un esfuerzo de encontrar una identidad cultural propia, diferente a la haitiana y la española. Por eso coinciden las primeras obras con los finales de la ocupación haitiana y nuestros esfuerzos independentistas: Javier Ángulo Guridi 
produce entre los intelectuales y artistas dominicanos una romántica exaltación del pasado autóctono, elevándolo a una categoría legendaria, con fines de legitimar los postulados ideológicos que sustentarán la identidad nacional en ciernes", y añade:

La idealización indigenista, bajo esa perspectiva histórica y emocional, tenía la deliberada intención de establecer "un nosotros" - como sucedió con el muralismo mexicano- capaz de crear por medio de una literatura apologética un rasgo de afiliación con el pasado y un sentimiento de identidad con lo propio, a partir de la sacralización de lo indígena y la exaltación de lo autóctono, como uno de los mitos fundacionales de la nacionalidad (García s/f: 18).

Por otra parte, al haber sido Santo Domingo el primer espacio de asentamiento hispano cuando aún la América estaba innombrada e incluso después, hizo de ella un espacio intenso de contacto interétnico entre españoles y negros esclavos con el indio, que - precisa Bernardo Vega - no duró más de medio siglo, ${ }^{14}$ "lo que necesariamente limitó el impacto que pudo haber tenido la cultura indígena sobre la dominicana" y añade, "algunos movidos por un romanticismo bien intencionado pero poco científico, exageran dicha influencia como un medio para subestimar la influencia africana, por razones de prejuicio" (Vega 1981: 11-12). Esa presencia e influencia africana en República Dominicana adquiría el carácter de un conflicto interétnico como consecuencia de las historias cruzadas con el vecino Haití. Primero Dessalines hizo varias incursiones en el espacio ve-

escribe sus poemas 'Maguana' (1840) y 'La cuita' (1842) y su hermano Alejandro escribe la novela Los amores de los indios (1843). Sin embargo, cuando mayor ímpetu toma el movimiento es después de la anexión a España y la guerra restauradora. En ese momento, nuestros hombres de letras tratan de mostrar que somos algo más que simples españoles, enfatizando nuestro antepasado precolombino. De esa fecha son Iguaniona (1867) y Escenas aborígenes (1872) de Javier Ángulo Guridi, Ozema o la virgen indiana (1867) de Félix María del Monte; el Enriquillo de Galván y las Fantasías indigenas (1877) de José Joaquín Pérez" (García s/f: 21).

14 Bernardo Vega expresa sin embargo su sorpresa por la "persistencia de ciertas herencias indígenas, a pesar de lo breve del periodo de contacto" (Vega 1981: 12) y precisa, "lo más utilitario fue lo que sobrevivió" (Vega 1981: 47). 
cino, más tarde Boyer extendió los dominios de la joven república hasta el territorio dominicano durante algo más de veinte años (1822-1844) y Faustin Soulouque, en 1849 y 1855, también hizo intentos por dominar la otra parte de la isla, todo lo cual influyó en la memoria colectiva dominicana, y propició la idea de un Haití agresivo e invasor.

Ese cruce de la frontera constituyó una herida en medio del territorio compartido. Todo vino al auxilio de unos y otros para generar una zanja profunda en lo étnico por los rasgos somáticos, lingüísticos y culturales, que, además de existir como cualidades diferentes de los grupos en interacción, se hizo sustancial en lo ideológico y en el imaginario social. La diferencia amplió las distancias y los contrastes aparecieron como cualidad para marcar una oposición. Entonces, y durante las primeras décadas del siglo xx, los procesos de autodefinición de la identidad dominicana se hicieron complejos y contradictorios en medio de crisis económicas, ocupación estadounidense (1915-1924) e inicio, en 1930, del gobierno del general Leónidas Trujillo. Todo el proceso, con implicaciones hasta nuestros días, fue de base histórica.

En ese contexto ¿cómo se orientó la búsqueda y expresión de la identidad nacional? ¿Cómo entró a la conciencia crítica de la cultura dominicana la realidad de que el negro de origen africano no está solo en Haití sino en el interior mismo de la relación etnia-nación? ¿Cuáles fueron las percepciones sociales, los imaginarios culturales y la dimensión ideológica de esos procesos en República Dominicana?

Andrés Serbin refiere cómo "los sectores hegemónicos recurren en diversos periodos de la fase poscolonial, a la incorporación en la ideología nacional de componentes étnicos no blancos [...] como ocurrió en el caso latinoamericano con su énfasis en el mestizaje y las raíces indígenas" (Serbin 1989: 266). En República Dominicana esas reacciones se expresaron por oposición al negro, lo que no fue un rasgo consciente en las teorías indigenistas de México y otros países latinoamericanos continentales, no obstante con ellas se desconoció de hecho su presencia y significación etnocultural. La historiografía da cuenta de los esfuerzos, aún insuficientes, por otorgarle valor a la existencia de este grupo social, llamado la 
tercera raíz, tan importante en la historia mexicana, por mencionar el territorio más cercano y de mayor interacción con el Caribe en los circuitos de hombres y mercancías que tuvieron lugar a través de su territorio y desde él hacia otros por la costa del Pacífico.

Pero en el caso dominicano la situación se presentaba algo diferente por ser la isla parte del sistema triangular atlántico, por haber tenido la vecindad con la mayor productora de azúcar y café del mundo con una altísima proporción de inmigrantes forzados desde África, y por la ocupación territorial haitiana después de la Revolución de 1804. Todos estos factores hicieron del tema, tanto en la historiografía tradicional como en el discurso del poder, un asunto alto sensible: "al querer negar la influencia del negro africano en la cultura nacional" - precisa Esteban Deivehan "inventado un esquema ideológico" que el trujillismo de cuño racista alimentó y "ha calado hondo en las capas del pueblo" (Deive 1981: 116), basado en la idealización de la categoría "indio" como fundamento identitario y cultural dominicano. Habitar esa "zona intermedia", como la denomina Silvio Torres Saillant, es expresión de la compleja experiencia racial dominicana más por consideraciones sociales que biológicas. Esa "indefinición del espacio intermedio permite una flexibilidad que puede contribuir a ocultar proyectos racistas". El término "indio" equivalía, precisa el autor, en lo cotidiano, al mulato, una persona de ancestro mezclado (Torres 1997: 249-250), que sería una tercera opción: ni negra ni blanca.

Lo paradójico se dio en la asunción de un indigenismo-otro, donde el indio se define como categoría étnica por oposición, pues ser indio es un modo de no ser negro, y en sus variantes se le fueron añadiendo adjetivos para una población criollizada. Entonces indio claro e indio oscuro fueron la expresión de esos tonos mezclados, y el negro es - esencialmente- el haitiano o sus descendientes. "Se precisaba acuñar un concepto homogenizador, que representara la enseña nacionalista y la unidad étnica de todo un pueblo plural y diverso, con el fin de lograr una imagen integracionista". El término "indio" se convirtió "en un arquetipo durante el proceso formativo de la identidad para denominar el crisol racial y cultural que encarna a los dominicanos. Y así, la identificación con 'lo indígena' facilitó 
en el país la creación de un nuevo color de piel, el color indio, con el cual se reconoce la mayoría de los dominicanos"15 (García s/f: 24). Adquirió el valor de una categoría de identidad psicosocial, "convertida en una salida que permitía al negro olvidar su origen inmediato [... ] y a quien la clase dominante había convertido en el antecedente de todos los grupos del Santo Domingo español" (García s/f: 24).

Estos factores históricos de un conflicto de expresión étnica tan peculiar sirvieron de pretexto a Dessalines en sus campañas de ocupación en los años del régimen haitiano en esta parte de la isla, así como abonaron a la permanente inquietud fronteriza que exacerbó el antihaitianismo ${ }^{16}$ como un tema también de identidad racial hasta llegar a su conversión en una ideología de Estado. "Durante la llamada 'Era de Trujillo' el término indio se generalizará en la autopercepción de los dominicanos" (García s/f: 29).

Sin embargo, la plástica dominicana no podía sustraerse de una realidad que -más allá de sus usos ideológicos por el poder instaurado- tenía ante sí como imagen. En el proceso de conformar una visión de lo propio y nacional, el negro emergió como figura dentro de la nación visual en obras de la primera mitad del siglo Xx: en los desnudos femeninos de Celeste Woos y Gil (Figura 2), o en ciertos temas de un artista que durante la década de los cuarenta se fue a estudiar a México (Darío Suro), como también en Jaime Colson que, aunque llega con una obra ya más consolidada y madura, no deja de advertirse en ella el influjo del muralismo y especialmente de la mirada hacia lo popular y el mestizaje.

15 Rubén Silé identifica esta situación como el "drama del hombre de color" y aporta una información de base histórica según la cual los negros recién llegados tenían la necesidad de hacerse pasar por oriundos de la colonia [...] y precisa que los fugitivos esclavos de la parte francesa que pasaban constantemente a la colonia española, con el fin de hacerse pasar por criollos de esta parte (negros libres o con posibilidades de comprar su libertad), como medio para disfrutar de las mismas ventajas empezaron a autodenominarse indios como forma de recurrir a lo más autóctono de la isla: sus primitivos habitantes (Silé 1981: 164).

16 Recuérdese el suceso sangriento de 1937, en contra de haitianos en la frontera, conocido como la Masacre del Perejil. 


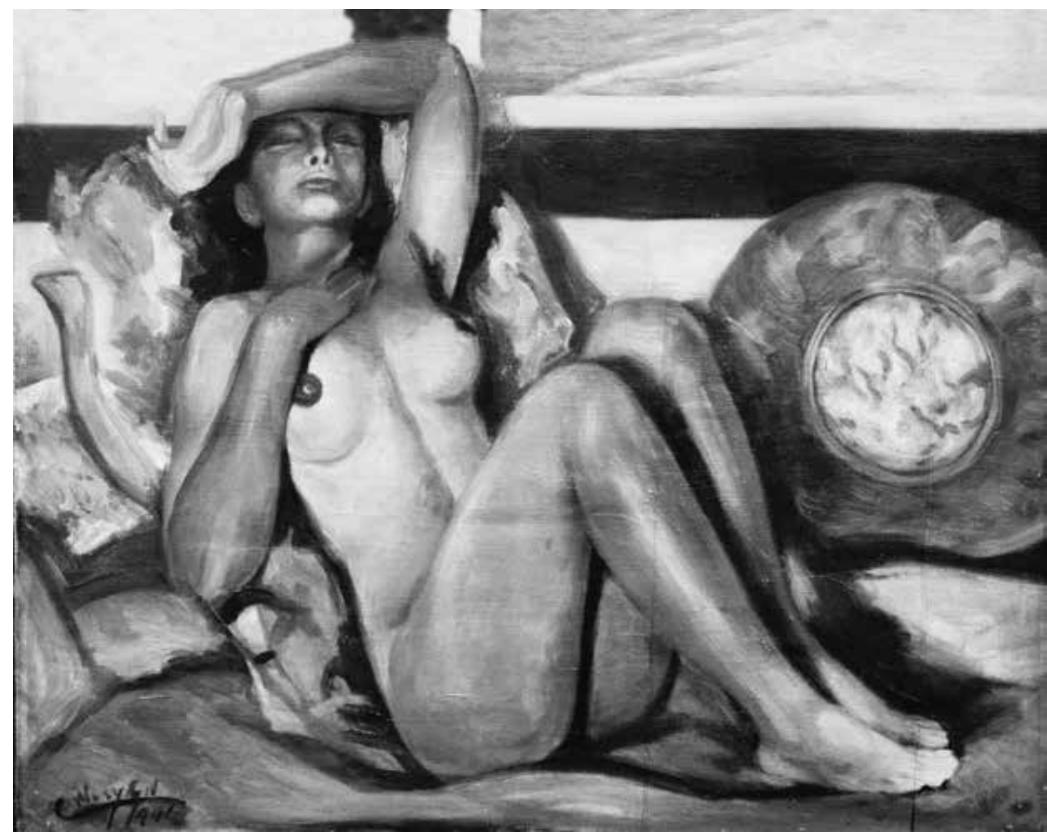

Figura 2. "Desnudo I", Celeste Woss y Gil, 1941, óleo sobre lienzo. Museo de Arte Moderno, Santo Domingo, República Dominicana.

INDIGENISMO Y NACIONALISMO EN HAITÍ

La República de Haití, la primera nación independiente de América Latina y la primera que abolió la esclavitud en el continente, fue ocupada por Estados Unidos en 1915. El sentimiento colectivo fue de una profunda infelicidad, ha dicho Michel Lerebours, y el movimiento de resistencia no se hizo esperar (Lerebours 1989: 180) como rechazo a la cultura del ocupante, lo que generó, en palabras del propio autor, "une révolte culturelle"17 entre los años 1927 y 1928. Se trató de un movimiento nacionalista que estuvo encabezado por figuras de gran prestigio no sólo en el campo sociopolítico sino también en la esfera intelectual.

17 "Revuelta cultural". La traducción es mía. 
Según Gérard Pierre-Charles, con la ocupación se abría "una fase moderna en la historia de Haití, caracterizada por la naturaleza neocolonial de sus relaciones con Estados Unidos y por el ordenamiento sociopolítico inspirado en el modelo organizativo estatal instaurado con la intervención" (Pierre-Charles 1978: 7). Y todo eso ocurría en Haití, que adoptó con su revolución de 1804, en la nueva constitución instaurada con la república naciente, el nombre originario que dieron los taínos al territorio: Haití (tierra de muchas montañas).

Sin embargo, la población mayoritariadel país fue traída desdeáfricay fue ella la que produjo durante algo más que un siglolas enormes riquezas que acumularon los plantadores, en su mayoría franceses blancos. Una insurgencia de esclavos ante esa hegemonía blanca francesa hizo triunfar la revolución, que ocurrió en varias etapas y regiones: una gran rebelión en la provincia del norte con enormes consecuencias para la colonia, así como varias sublevaciones en el oeste y sur.

Entonces, el indigenismo haitiano, ha dicho Glodel Mezilas, surgido al calor de la ocupación es, "a diferencia del latinoamericano [...] un indigenismo sin indígenas o que connota un concepto metafórico de indígenas (los haitianos), en el sentido de que son los dueños del país frente a toda intervención imperialista" (Mezilas 2008: 2).

Ese movimiento indigenista constituyó un momento de reivindicación de la haitianidad en el proceso constructivo de una identidad. El indigenismo en Haití, sin indígenas, los reivindica y busca afincarse en lo originario americano como un modo de entablar alianzas con otras tierras continentales que gestaban un imaginario cultural de la nación..$^{18} \mathrm{En}$ el

18 "Es menester rastrear el origen del concepto indígena en Haití. El uso de este término remonta a la época de la independencia en 1804. El ejército de liberación nacional que enfrentó las tropas de Napoleón Bonaparte se llamó 'ejército indígena' para significar que los haitianos eran los dueños del país, recuperando la memoria colectiva de los primeros habitantes de la isla. Un ejército indígena luchó contra un ejército extranjero, colonialista e imperialista. En este caso, el calificativo no se refiere estrictamente a los indígenas sino a los esclavos en lucha contra una potencia extranjera. Es un término nacionalista y antimperialista e incluso bélico. Así, el imaginario indígena estuvo muy presente en ese tiempo. Por esta razón, Jean Jacques Dessalines rechazó para el país el nombre colonial de Saint Domingue o La Española, que designaba a toda la isla, 
editorial del primer número de la Revue Indigène ${ }^{19}$ fundada en 1927, en la que se reunieron escritores de la talla de Émile Roumer, su director, y sus fundadores Normil Sylvain, Carl Brouard, Daniel Heurtelou, entre otros como Jacques Roumain, figura joven entonces que llegó a ocupar un distinguido lugar en las letras haitianas con obras como Los gobernadores del rocio, y que - consecuente con sus postulados humanistas y progresistas - fundó el Partido Comunista de su país.

En esa crónica-programa se exploran los fundamentos conceptuales del movimiento indigenista. Resulta muy interesante el epígrafe llamado "La América Latina y nosotros", ${ }^{20}$ en el que su autor, Normil Sylvain, decía que "somos culpables de ignorar la América Latina porque los orígenes son similares y un gran peligro común nos amenaza" (Sylvain, 1927: 6), y precisaba, "debemos conocer más la literatura y el alma de América Latina. Esos pueblos han vivido una vida tan difícil como la nuestra [...] vicisitudes parecidas", y expresaba que, si los historiadores intentaban explicar la causa de sus males a partir de su condición de indios, en el caso haitiano, la situación se presenta similar, pero por negros. Con lo cual, desde su poética inicial, la revista proyecta una conexión de base histórica y social sobre los males comunes que aquejan a nuestros pueblos, de indios y de negros, continentales e insulares, y enfoca una mirada hacia Latino-

para adoptar un término prehispánico: Ayti, con lo cual reveló su intención de acabar con el colonialismo, la esclavitud, el imaginario colonial y la dominación francesa. Walter Mignolo destaca que el nombre Ayti marca la transformación histórica y epistémica introducida por la revolución y se aparta de la época de la esclavitud y el dominio imperial francés. Asimismo, en el Acta de Independencia del país, que fue el primer monumento literario por la manera en que fue redactada, aparecieron los términos 'ejército indígena', 'ciudadanos indígenas', 'indígenas de Haití'. Esta constante repetición del calificativo indígena no carece de importancia simbólica. La memoria del violento genocidio de los indígenas estuvo muy presente en la lucha por la independencia" (Mezilas 2008: 2).

19 Consúltese en Biblioteca Digital del Caribe http://dloc.com/UF00095935/00001/1j.

20 "Nous sommes coupables d'ignorer l'Amérique Latine parce que les origines sont semblables et un grand danger commun nous menace". Las traducciones de la Revue Indigène han sido realizadas por la autora. 
américa desde las historias que se entrelazan. ${ }^{21}$ Sylvain sitúa los conflictos compartidos: más allá de las razas o pertenencias étnicas, en la condición común de hombres, ${ }^{22}$ y entonces precisa "como se hace una manera de insulto de la palabra indígena, la reivindicamos como título, el punto de vista del indígena. Un retorno a la sinceridad y a lo natural" (Sylvain 1927: 9). ${ }^{23}$

En esta visión fundadora del indigenismo en Haití, sin pretensiones de buscar falsos nexos con las tendencias en Latinoamérica y en México, se aprecia la denominación como un atributo de dignificación del pasado glorioso en el que lo indígena y lo africano encuentran sitio originario, lo que en el caso haitiano implicaba un enraizamiento en la tierra y su historia como sentido de pertenencia y de defensa de lo propio. Por eso los fundamentos identitarios de la nacionalidad haitiana se sustentaron en la cultura popular, en el universo campesino y los imaginarios de las creencias procedentes de África, así como la lengua créole, todo nacido en el país y auténticamente de allí.

Ese indigenismo no fue una puesta en valor de lo que ya estaba allí cuando los conquistadores llegaron -aunque lo incluyera- sino de lo que surgió como resultado de ese mismo proceso, de lo que nació y creció en el territorio asumido como una pertenencia a defender en tanto que valor cultural: "el movimiento indigenista haitiano [es] un movimiento cultural que reivindica la nación desde sus mitos, sus fábulas, sus leyendas, para rechazar y recuperar su soberanía violada por la intervención extranjera"

21 En su texto, Normil Sylvain hace referencia a un destacado grupo de autores y obras de los países de Latinoamérica. De México menciona especialmente a Sor Juana Inés de La Cruz, Amado Nervo, Alfonso Reyes y José Vasconcelos, figura muy ligada al tema del indigenismo mexicano, como se sabe. Se aprecia un interés por resaltar los valores de la cultura latina, la patria latina ("la patrie latine") en oposición al utilitarismo de la cultura anglosajona ("à l'utilitarisme anglo-saxon") como acto de reivindicación ante la ocupación estadounidense. Por ello también traducen al francés, en las páginas de la Révue Indigène, a grandes poetas latinos, como Carlos Pellicer y Manuel Acuña (Sylvain 1927: 6-8).

22 "Il n'en est rien, si nous avons souffert, si nous avons connu les mêmes angoisses placés sous des ciels semblables, dans des circonstances presque identiques, ce n'est ni parce qu'indien, ni parce que nègres, mais parce que hommes" (Sylvain 1927: 6).

23 "Comme on fait une manière d'insulte du mot indigène nous le revendiquons comme un titre, le point de vue de l'indigène. Un retour à la sincerité et au natural". 
(Mezilas 2008: 33). Y claro, no fueron los únicos modos de enfrentar la ocupación; Charlemagne Péralte y Benoît Batraville tomaron las armas. Fueron figuras emblemáticas de la resistencia y llegaron a movilizar a los campesinos, pero el enemigo los superaba, fueron vencidos y ejecutados por las tropas norteamericanas (Mezilas 2008: 33).

Se trató de un momento de confrontación en todos los órdenes, durante el cual se construyen bases fundamentales para la nueva sensibilidad cultural que implicó el pensamiento indigenista, como la aparición, en 1928, de Así babló el tío, de Jean Price Mars, un libro que a través de la oralidad popular recorre aspectos muy sensibles del imaginario haitiano, así como la valoración del vudú y el créole como insignias fundamentales de la nación cultural. La pintura del indigenismo partía de la ruralidad y el mundo campesino, la pobreza de los espacios y la humildad de sus habitantes. El indigenismo propuso una nueva mirada artística a partir de una expresión nacional, entendida como "un lugar común en el cual el hombre haitiano se reconociera a sí mismo" (Saint-Eloi 1993: 127). La mirada giró hacia el interior del país, fue privilegiada por artistas nativos como Pétion Savain (Figura 3) en su pieza "Las lavanderas" (1934) y en las ilustraciones que realizó para su novela La cabaña de Damballab (1938). En ellas, penetra en aspectos de la religión popular que permanecían aún fuera del universo visual de las artes plásticas, y que adquirirán una visibilidad más significativa cuando la obra de Héctor Hypolitte, desde el Centro de Arte fundado en 1944, enuncie una marcada personalidad en el arte haitiano y a escala internacional. En los dibujos de Savain la naturaleza se impone, pero no por su exuberancia, sino por un tronco centenario que muestra sus raíces afincadas en la tierra, todo un símbolo telúrico ante el cual la figura humana y su ámbito doméstico entablan -por sus escalas- un profundo contraste. Georges Remponeau, en la pieza "Lamentin" (1934) (sitio de una antigua fortificación colonial de la que no subsiste ninguna huella ni en la realidad ni en el cuadro), ha pintado un palmar, símbolo de identidad en el paisaje, una metáfora conforme en todo sentido con el espíritu nacionalista de los indigenistas. 


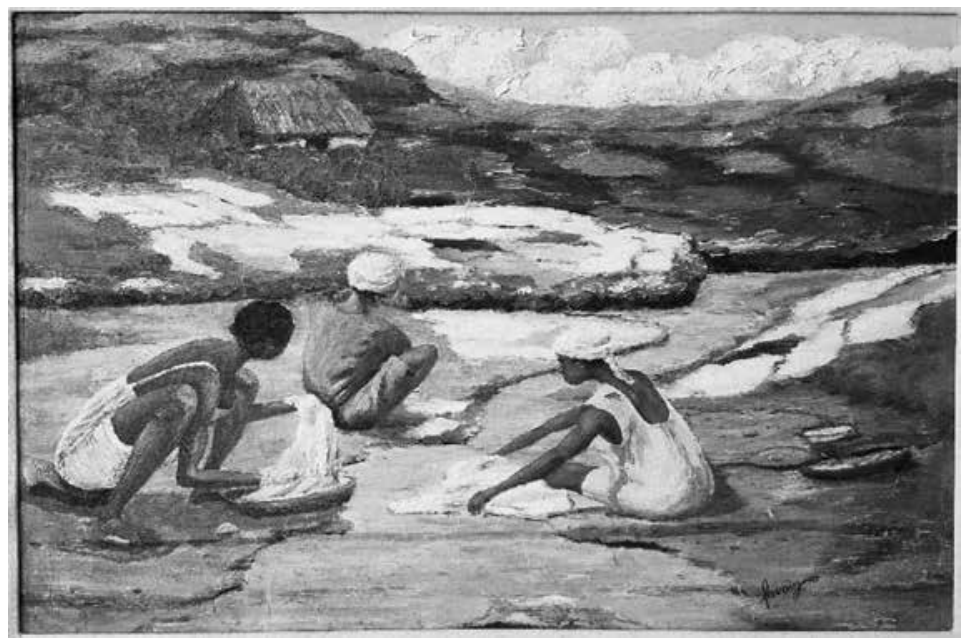

Figura 3. "Las lavanderas", Pétion Savain, 1934, óleo sobre lienzo. Colección Laleau, Estados Unidos.

CUBA, EL ARTE DE MÉXICO, EL INDIGENISMO Y MÁS

Desde el siglo XIX, en las letras y las artes cubanas se distingue un acercamiento al nativismo y al costumbrismo, los que, ha dicho Cintio Vitier, se encuentran "a un paso del indigenismo" (Vitier 1970: 155), y cree que es algo fantástico porque "nuestros indios, de tan débil perfil y tan escasa cultura conocida, se habían extinguido sin dejar memoria válida para la creación poética sistemática" (1970: 158). Se trata de un vacío cultural que la intelectualidad comenzó a llenar por los caminos de la escritura con la nostálgica visión romántica del encuentro del sujeto con su espacio natural. Las obras de Plácido, "Al Yumurí", y las de José Fornaris, "Los cantos del siboney" (1855), ponen su atención sobre aquellas comunidades destruidas por la conquista y la colonización. Eran momentos en los cuales la isla se levantaba contra el dominio español, y las tendencias del pensamiento político y social reflejaban un universo de contradicciones en la orientación de los acontecimientos que en 1868 inauguraron, con el Grito de La 
Demajagua, el inicio de las guerras de independencia. Entonces el tema nacional se hizo decisivo en el pensamiento cubano.

Llamó la atención de Vitier que el libro de Fornaris hubiera tenido varias ediciones, lo que no era nada frecuente en su época y menos aún con un texto que hacía referencia a las comunidades aborígenes del país. Se detuvo a buscar algunas causas posibles de tal acontecimiento. En el prólogo de Fornaris a la edición de 1888 expresa:

Sólo bajo una forma simbólica hubiese podido expresar el amor a la patria y protestar contra el modo injusto e insolente de regirla. La palabra patria sonaba como un grito insurrecto en el oído de los gobernantes. Por esta razón Los cantos del siboney tuvieron cinco ediciones sucesivas, único caso en la época en Cuba [...] Bien sé que esto obedecía a la idea que los versos encerraban, se veía en ellos un símbolo en el que los indios siboneyes representaban a los cubanos oprimidos y a los indios caribes como los injustos opresores (citado por Vitier 1970: 159).

Y precisa Vitier que por eso el general don José de la Concha llamó a Fornaris al Palacio de los capitanes generales y le dijo: "Le he mandado a llamar para advertirle que si desea continuar escribiendo sobre siboneyes vaya a hacerlo a los Estados Unidos. Aquí somos españoles y no indios" (Vitier 1970: 159).

El escritor había hecho una utilización alegórica del tema y sus personajes individuales y colectivos entrecruzaron mensajes como pretexto para expresar las confrontaciones con los llegados de afuera y remontar así los tiempos de la historia, por lo que Fornaris precisaba que " mis cantos fueron más un símbolo que la historia de una raza", lo que ratifica el propio Vitier cuando afirma que "el único vínculo real con el indio, en efecto, está en el paisaje virgen [... e en las soledades agrestes" (Vitier 1970: 160).

En fin, que la naturaleza constituyó un enlace con el pasado originario, la penetración al espacio virgen, un recurso hacia lo desconocido e ignoto con nostalgia de lo perdido, como se apreciará en las tendencias siboneyistas que siguieron, en la poesía de Joaquín Lorenzo Luaces y Juan Cristóbal Nápoles Fajardo, conocido como El Cucalambé, quien en obras como Hatuey y Guarina o El cacique de Maniabón, no sólo retoma asuntos aborígenes sino - y quizás es muy interesante- que lo hace 
con aires de décima guajira, lo que articula una relación entre el universo ancestral del indio con los habitantes de la campiña cubana. La literatura fue reveladora de estas tendencias y las artes plásticas de cierto modo también, aunque el lenguaje dominante del academicismo tradicional le dio un toque de mayor grandilocuencia estilística a ciertas representaciones de temas indígenas bajo los influjos del neoclasicismo que se había hecho rampante. La vertiente romántica más centrada en el paisaje en la obra de Esteban Chartrand otorgó a la campiña cubana un sentido lírico e idealizado, en consonancia con la élite burguesa a la que perteneció el artista y que fue su mayor comitente. Como en todo lo virginal y primigenio, se aprecian las marcas de una cierta ahistoricidad, un vaciamiento de sentido histórico. El indio no está allí, ni tampoco en los numerosos grabados realizados por artistas viajeros entre los siglos XVIII y XIX, como sí se aprecia en los recorridos por territorios continentales.

El siglo xx vio izarse, el 20 de mayo de 1902, la bandera cubana en la isla, después de cuatro años de ocupación estadounidense que interrumpieron el largo proceso independentista de más de 30 años. Es posible imaginar el sentimiento de frustración nacional ante la farsa de aquella república que nació enmendada en su constitución y atada económicamente a los Estados Unidos por un tratado de "reciprocidad" comercial que beneficiaba sus intereses y hacía a la isla altamente dependiente en su condición neocolonial. El proceso de recuperación de las fuerzas progresistas fue lento ante el estado de amenaza permanente que significaba la condición de protectorado del país del norte.

Al inaugurarse el pasado siglo y en el decurso de sus primeros decenios, el indio no fue una referencia fundamental cuando la intelectualidad cubana comenzó a indagar sobre los factores constitutivos de la identidad nacional en el plano artístico-visual. La estimación de ese legado se había hecho presente en los estudios precursores de la antropología física a través de la obra de Luis Montané, fundador del primer museo de su tipo en el país, y en otros campos de las ciencias sociales que llenaban paulatinamente el vacío aparente de los siglos que precedieron a la conquista y la colonización. Cuando hacia los años veinte del pasado siglo la intelectualidad 
cubana comenzó a indagar sobre las matrices culturales para la fundación de una imagen de autenticidad cubana, el indio fue parte de lo que Jesús Guanche ha dado en llamar "el etnos-nación cubano", con sus diversos componentes debido a migraciones externas, por lo que, " no se define por rasgos raciales" sino por distintos niveles de mestizaje interracial, no sólo "se ha nutrido de sus elementos originarios [...], o sea, de sus raíces" (Guanche 1996: 118, 129).

El indio quedó subsumido en esa amalgama, también llamada ajiaco por el gran estudioso de la sociedad cubana, Fernando Ortiz, lo que producía una tal combinación de sabores que resulta difícil poder reconocer cada uno de sus ingredientes. De algún modo lo indígena quedó así diluido en la fusión, estaba allí pero su invisibilidad se hizo patente. El tema negro era tan sustancial a la expresión cubana, sus particularidades eran tan significativas en aportes psicosociales en la vida nacional que fue mayor centro de atención que el universo indígena en el momento de fundar una imagen de identidad a través de la literatura, la música o las artes visuales.

Las circunstancias nacionales hicieron madurar un proceso cultural marcado también intensamente por el contexto. Fue hacia los años veinte y treinta que esas tendencias favorecieron la marcha de los acontecimientos, y todo se integró de manera coherente. Un arte nacional se presentó como una oposición a las tendencias elitistas de la academia y a sus maneras artísticas de satisfacer el gusto del sector dominante. Un arte otro, para ser sensible al espíritu nacional, se propuso ser "nuevo", lo que significaba, en la poética de los creadores, ser antiacadémico y poner en valor lo local con sentido de responsabilidad social. Formados como estaban en el propio espacio tradicional que se proponían cambiar, fueron a buscar las experiencias en espacios artísticos de ruptura; primero Francia y después México. Los resultados fueron diversos, como diferentes fueron las maneras individuales de cada creador. Ciertas plataformas fueron esenciales para encontrar los caminos grupales, las revistas, especialmente Revista de Avance (1927-1930); las exposiciones colectivas como "Arte Nuevo" (1927), patrocinada por la misma publicación, y otras sucesivas; así como la elaboración de ciertos proyectos artísticos en los que se aprecia una profunda influencia 
del México que democratizó la cultura a partir de sus artes e instituciones después de la Revolución de 1910. Se habían abierto canales de información y comunicación por diversos medios, en particular las publicaciones que hacían una trayectoria desde Cuba hacia México y viceversa, y los viajes de artistas que comenzaron a ser más frecuentes. El gran país continental atrajo las miradas de muchos de los intelectuales y artistas cubanos.

El arte de México sentaba pautas que la intelectualidad no desconoció ni ignoró. Su acercamiento fue consciente y con marcada intencionalidad crítica hacia el contexto cubano; muchas de las prácticas que allí se aplicaron fueron procesadas en función de la realidad nacional, diferente a la del país de referencia en etapa posrevolucionaria. Los procesos sociales y culturales que siguieron a los acontecimientos de la Revolución mexicana, signados por su proyección social y democrática para las artes plásticas, repercutieron muy sensiblemente en la creación visual de Cuba. Esa experiencia artística nutriente fue otra vanguardia para los artistas cubanos en cuyos proyectos y expresiones creativas vibró una profunda inspiración mexicana, como la del muralismo y escuelas libres que un destacado grupo de artistas cubanos presentó al gobierno en 1933.

Entre esos artistas se encontraba Mariano Rodríguez, que estudió en la Academia de San Carlos. Sus años de aprendizaje fueron decisivos y definieron "una etapa mexicana", tectónica en la forma, terrosa en el color y comprometida socialmente (Figura 4). "Unidad" (1938) resume esas influencias y con ella se sitúa en el centro del debate estético cubano de su época. Uno de los críticos más influyentes, Guy Pérez de Cisneros, buscaba otras explicaciones a esos seres gigantescos y fornidos con los que llegó Mariano de México, "la estatuaria y el empleo de colores demasiado seguros [...] de símbolo y expresión ruda" (Pérez 1939: s/p), los que interpretaba como una contrapartida a la pintura precedente. Lo cierto es que Mariano producía un cambio en el sistema de valores artísticos que el gran pintor cubano Carlos Enríquez también criticaba, tanto por los "remedos picassianos" como por los diego-riveristas (así lo escribía) (Enríquez 1941: s/p). De modo que el referente artístico de la creación mexicana se distinguía como una novedad visual pero descontextualizada, como lo precisaba en "Esquema de la pintura moderna en Cuba", Ramón 
Guirao: "El muralismo monumental del arte indígena es otra de las evasiones de la esencia misma de la cubanidad [...] no se trata de aclimatar estéticas americanas o europeas sino de reincidir lo suficiente con sentido crítico y afán de depuración hasta lograr nuestra expresión más justa y total" (Guirao 1941: s/p). En la obra de Alfredo Lozano también se aprecian los aportes de su estancia en La Escuela Libre de Escultura y Talla Directa de México y de haber recibido clases de dibujo en la Academia de San Carlos de donde regresó en 1937. También se incorporó a la experiencia del Estudio Libre como instructor. Su pieza "El abrazo" (1938), realizada en piedra (Figura 5), es otro interesante ejemplo de ese referente mexicano que marcó la obra de algunos representativos artistas cubanos y que se expresó más allá del indigenismo como imagen visual de su tiempo.

Esa experiencia artística nutriente fue otra vanguardia para los artistas cubanos en cuyos proyectos y expresiones creativas vibró una profunda inspiración mexicana, como los de muralismo y escuelas libres, que un destacado grupo de artistas cubanos presentó al gobierno en 1933 (Wood 2005).

\section{CONCLUSIONES}

Durante los primeros decenios del pasado siglo los indigenismos antillanos respondieron a procesos marcados por la inestabilidad política y la injerencia extranjera. Se manifestaron de diversas formas y tuvieron como rasgo común una intención de valor psicosocial en la construcción identitaria y nacionalista como tendencia de la época. Los indigenismos antillanos surgieron de sus propias circunstancias históricas, lo que contribuye a enriquecer la mirada sobre un tema de tanta importancia. La influencia del arte de México marcó esas referencias por los intercambios y viajes de estudio, por la sensibilidad hacia lo popular y lo autóctono, y fueron asumidas también de manera polémica tomando en cuenta los precedentes y las trayectorias de los procesos creativos insulares, lo cual revela un referente asumido críticamente desde la fundación de una imagen en las islas mayores del mar Caribe. 


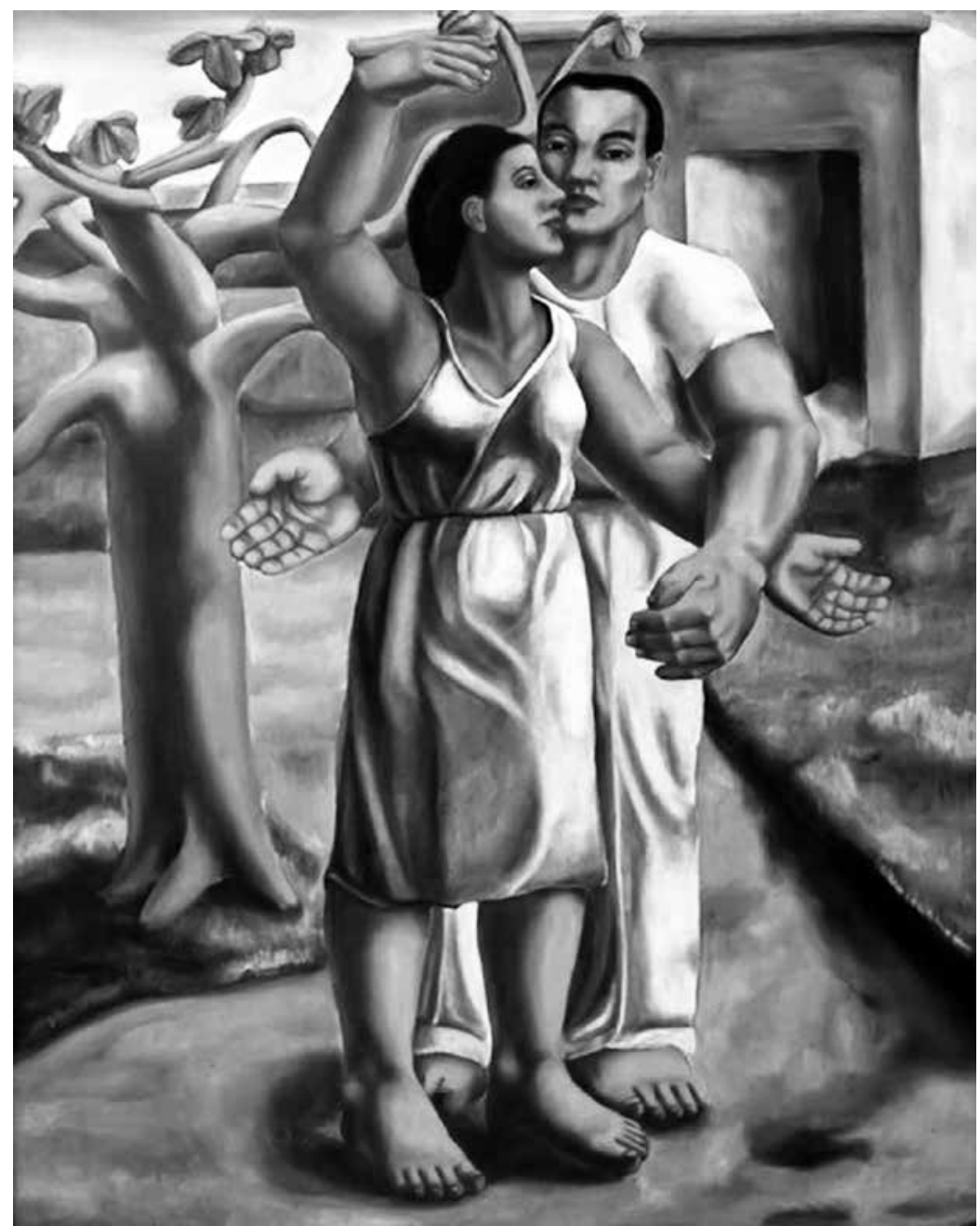

Figura 4. "Unidad", Mariano Rodríguez, 1938, óleo sobre lienzo. Museo Nacional de Bellas Artes, La Habana, Cuba. 


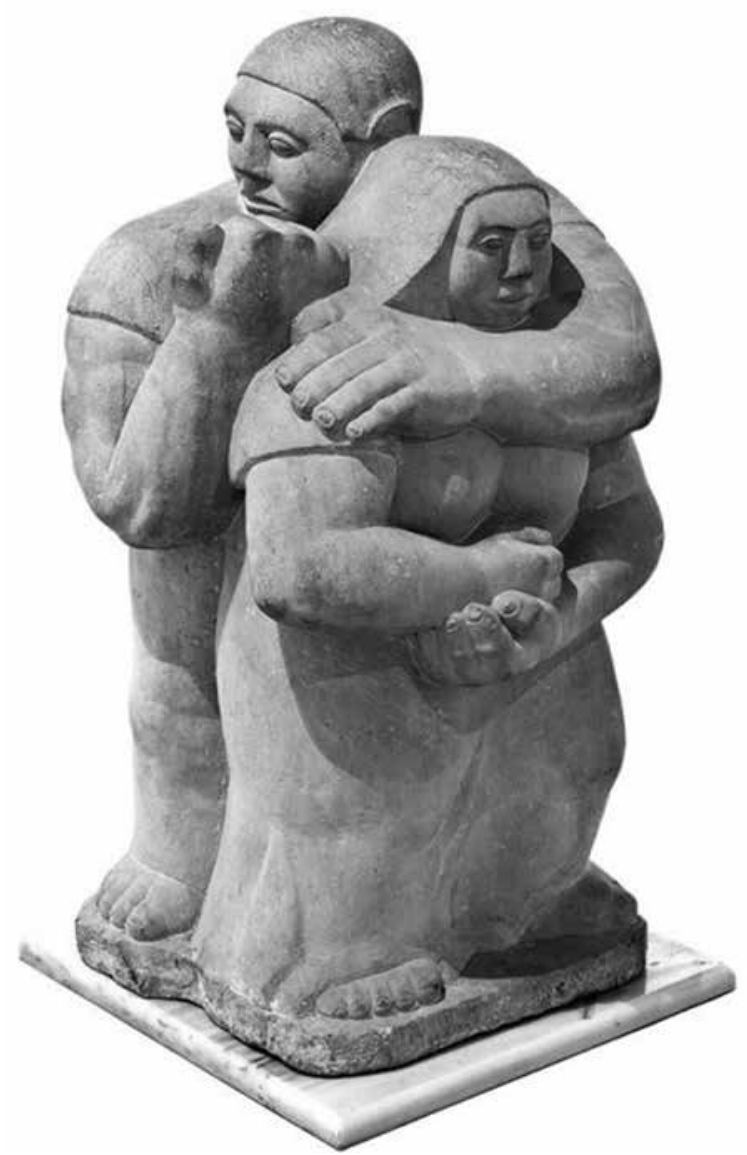

Figura 5. "El abrazo", Alfredo Lozano, 1938, escultura en piedra. Museo Nacional de Bellas Artes, La Habana, Cuba.

BiBLIOGRAFÍA

Biblioteca Digital del Caribe. La Revue Indigène. Disponible en http:// dloc.com/UF00095935/00001/1j (Consultado el 7 de enero de 2019). BRADING, DAVID. Los orígenes del nacionalismo mexicano. México: Ediciones Era, 2004. 
Deive, Carlos Esteban. "La herencia africana en la cultura dominicanana actual". Ensayos sobre cultura dominicana. Santo Domingo: Museo del Hombre Dominicano, 1981: 105-141.

DELGADO, OSIRIS. Ramón Frade León: pintor puertorriqueño (1875-1954). Un virtuoso del intelecto. San Juan: Centro de Estudios Avanzados de Puerto Rico y el Caribe, Instituto de Cultura Puertorriqueña, 1989.

\section{Cultura Puertorriqueña,1990. 4-7.} $\mathrm{R}, 1976$.

Enríquez, Carlos. "De Enríquez a Guy Pérez de Cisneros". La Habana, El Nuevo Mundo, 7 de septiembre de 1941.

Galván, Manuel. Enriquillo. Prólogo de José Martí. República Dominicana: Ediciones del Taller, 1989.

García Arévalo, Manuel. "El indigenismo dominicano". Mar Oceana 24 $(\mathrm{s} / \mathrm{f}): 15-32$.

GAYA NuÑO, ANTONIO. La pintura puertorriqueña. Soria: Centro de Estudios Sorianos, 1994.

GonZÁLEZ, José Luis. El país de cuatro pisos y otros ensayos. Puerto Rico: Huracán, 1980.

GuANCHE, Jesús. Componentes étnicos de la nación cubana. La Habana: Fundación Fernando Ortiz/Ediciones Unión, 1996.

GuiraO, Ramón. "Esquema de la pintura moderna en Cuba". Revista de Arquitectura 100 (1941): s/p.

LANDING GORDON, HAYDÉE. El nacionalismo como forma de afirmación en las artes plásticas puertorriqueñas 1900-1985. Tesis de Maestría en Artes Visuales, México: unam, 1986.

Lerebours, Michel PHilipPe. Haití et ses peintres. De 1804 à 1980. Port-auPrince: Imprimeur II, 1989.

MeZILAS, GLODEL. "Qué es el indigenismo haitiano". Cuadernos Americanos 126 (2008): 29-52.

MuÑIZ RoJAS, IvóN. "Identidad vs renovación en la pintura puertorriqueña de inicios del siglo xx". Anales del Caribe 10 (1990): 235-247. 
PÉReZ De Cisneros, Guy. "Sexo, símbolo y paisaje". Espuela de Plata 1 (1939): s/p.

PIERRE-CHARLES, GÉRARD. Haití: la crisis ininterrumpida 1930-1975. La Habana: Fondo Editorial Casa de las Américas, 1978.

Torres Saillant, Silvio. "Hacia una identidad racial alternativa en la sociedad dominicana". Puerto Rico. Extramuros 9 (1997): 235-252.

SaInT-EloI, Rodney. "Peinture et indigènisme". Conjonction 197 (janviermars 1993): 125-149.

SAladino García, AlBERTO. Indigenismo y marxismo en América Latina. México: CIALC-UnAM, 2016.

SERBIN, ANDRÉS. "La dinámica etnia-nación en el Caribe y sus efectos regionales". Anales del Caribe 9 (1989): 261-269.

Sylvain, Normil G. "Cronique-Programme". La Revue Indigène 1.1 (1927): $1-10$.

SiLIÉ, RuBÉn. "El hato y el conuco: contexto para el surgimiento de la cultura criolla". Ensayos sobre cultura dominicana. Santo Domingo: Museo del Hombre Dominicano, 1981: 143-167.

VAL, José DEL Y CARLOS ZOLLA. Documentos fundamentales del indigenismo en México. México: Unam, 2014.

VEGA, BERNARDO. "La herencia indígena en la cultura dominicana hoy". Ensayos sobre cultura dominicana. Santo Domingo: Museo del Hombre Dominicano, 1981.

Veloz Maggiolo, Marcio. Sobre cultura y política cultural en República Dominicana. Santo Domingo: Editorial Alfa y Omega, 1980.

VILLORO, LuIs. Los grandes momentos del indigenismo en México. México: El Colegio de México, 1950.

VITIER, CinTio, Lo cubano en la poesía. La Habana: Editorial Letras Cubanas, 1970.

Wood, Yolanda. Proyectos de artistas cubanos en los años treinta. La Habana: Editorial Letras Cubanas, 2005. 